\title{
Indexing in Source
}

\begin{abstract}
Analogous to the Cataloging in Source (CIS) project, the Indexing in Source (IS) suggests that magazine editors assign subject headings in their publications, along with the table of contents. The subject entries should be those used by the accredited indexing services. The system should shorten the procedures of indexing institutions and establish a new mechanism of selective indexing in the libraries themselves. Objections from publishers, which were valid in the CIS project, can be eliminated in IS.
\end{abstract}

$\mathrm{T}$

HE GROWING POPULARITY of periodical literature has one fundamental reason: speed. This glorious phenomenon, which complies perfectly with the idea of supersonic civilization, drives more and more readers to the periodicals desk, where they expect (1) up to date information; (2) on the most recent topics; (3) in the speediest way.

Quick services are, however, rare, and fast orientation is a matter of chance. Reference work with periodicals relies heavily on indexing and abstracting services and, again, the velocity of their operation. Most likely this is also the area where much could be done to accelerate readers' services and cut the time gap between a ready publication and its availability.

The familiar indexing journals (Readers Guide, Social Sciences \& Humanities Index, Education Index, and others) are striving bravely against time. The Readers Guide is one of the fastest services in the world for nontechnical journals. These indexes are, however, very limited in scope. The $R G$ covers only 130 journals, the Social Sciences of Humanities Index, 210, the Business Periodicals Index, 170, and they very often overlap each other.

Dr. Vesenyi is Reference Librarian in Hunter College in the Bronx.

It would be unsafe to make comparisons between similar indexing operations here and abroad. The size of a country might be a determining factor. Small countries often have centralized and very comprehensive services covering three to four hundred titles, virtually the whole output of the country, prepared by scholarly institutions (e.g., Denmark, Sweden, Hungary). Large countries, however, are forced to specialization, which often results in duplicated efforts and lack of perspicuity. Large output can hardly be handled otherwise, especially when speed is one of the principal aims to be achieved.

Nevertheless, there is a good chance to conquer time in any country by a simple operation, which could be called "Indexing in Source (IS)" after the "Cataloging in Source (CIS)" project.

CIS, although it did not reach all its goals, turned out to be a durable success. Despite the agonizing years of the birth of this important experiment, a century-old dream of librarians became true. It was, however, no miracle. "A man's dreams have a habit of coming true," wrote Halldór Laxness. So let us see how another dream, the IS, could work while becoming true.

Indexing in Source suggests that any periodical, journal, or magazine should designate the subject entry of its articles 
in the table of contents or in an easily accessible separate column. The subject entries should be the same as are used by the accredited indexing services.

This sounds very simple, and, in fact, it is much simpler than the procedure of the CIS. There is no problem of getting accurate bibliographical information, particularly regarding imprint and collation, no mailing arrangement has to be made for sending the proof to the $\mathbf{L i}$ brary of Congress, nor is there waiting for its return with catalog entry to the publisher. The editor simply chooses the most suitable subject heading and prints it with, or beside, the table of contents in every issue. It is granted, naturally, that the editor, who is familiar with his subject field and who reads the published articles and other features, has competence to assign subject headings without cooperation from any library. A sort of uniformity in the presentation can be settled in a later phase of the project.

The consequences of this process have many implications. First of all, articles of the magazine need not be read by the indexer at the indexing institution. Thus one of the most time-consuming factors can be eliminated and the time gap reduced. It should be noted also that significant saving is achieved by shortening the working procedure of the indexing service, which could be used for extending the coverage to other titles.

Furthermore, IS might play an important role in building up machine indexing systems. Machine indexing is still in an experimental state in the field of science and technology (such as Chemical Abstracts and Physics Abstracts) but no such experiment is operational in social sciences and humanities, to which IS is principally directed.

Indexing in Source offers an even more dramatic perspective at the very heart of periodical services in the library.

For demonstration only one type of li- brary has been chosen, with the assumption that the scheme can be adopted by other kinds of libraries. The library discussed here is a middle sized senior college library, with about five hundred current periodical subscriptions. Well established statistical data prove that in such a library an average of ten issues annually will be received per periodical title which amounts to a total of five thousand issues yearly. It means also that about twenty single periodical issues arrive daily at the library (on a five-day-week basis).

If a clerical employee would spend an hour or two in going through the tables of contents of those twenty magazines and item by item enter the features on a pre-printed form under their subject headings, the readers would have the most up-to-date index ever used. Professional assistance is scarcely needed. The operation is economical from every aspect. As for the form, it seems to be convenient to use prepunched sheets with printed subject headings. A ledger book would keep the indexed material together.

Names of persons and authors should be entered in a separate alphabetical list, though it must be emphasized that the aim of the project is principally to give fast orientation in subject fields, not authors.

The project is also versatile. One may index only part of his periodical receipts, assign special titles of journals, choose particular subject fields, or ask the teaching faculty for suggestions concerning the curricula. He may also vary from time to time the selection of material indexed. In any case, the IS gives an opportunity to have index data the very same day, or the day after, a periodical appears. This prospect appears to be remarkably useful for library patrons and might even change research schedules.

Publishers doubtless will have objections, as they did in the case of the CIS. But in general they were willing then to cooperate, after the officers of the $\mathrm{Li}$ - 
brary of Congress traveled far and wide, visiting thirty-eight cities and twentyone states in order to persuade them. ${ }^{1}$

R. B. Eastin stated ${ }^{2}$ that the CIS project would have much more appeal to the publishers if it would result in increased sales. Although the project resulted in substantial savings to the libraries, it was not possible to estimate how much of this saving might have been reflected in additional book purchases.

As far as periodicals are concerned, however, we are able to present some facts to the publishers, which might affect their financial interest.

1. It has been ascertained by many librarians that if a periodical is not indexed, it "just doesn't exist" for a considerable number of library users.

2 . If the time gap between the publication's date and the availability of the index is too wide, the reader very easily loses interest in that particular journal.

These two factors might influence a library in its selection as to which journal should be subscribed. Advertisers, natu-

\footnotetext{
${ }^{1}$ R. B. Eastin, "Cataloging in Source: the Viewpoint of Publishers," LRTS III (Fall 1959), 253-56.

2 Ibid.
}

rally, also prefer those publications which are read by many people soon after appearance. Advertising is something always respected by publishers.

\section{Summary}

Analogous to the Cataloging in Source project, the Indexing in Source plan promises significant gain in speed of various processes. This is obvious at the indexing institutions and by establishing a new mechanism of indexing in the libraries themselves. Objections which were valid in the CIS project can be eliminated in IS. The project also seems to be advantageous financially for indexing services and publishers alike, and also beneficial for the research worker. The flexibility of the plan, as to putting the publishers' contribution and the libraries' indexing on selective basis, makes the Indexing in Source easily adjustable for all parties involved.

A basic necessity, however-the publishers' participation-will probably be most easily elicited by our professional organizations, such as LC, ALA, CRL, and the American Standards Association. 